\title{
Human FcRn Can Mediate the Transport Across Intestinal Mucosal Barrier and Prolong the Half-Life of Rabbit IgG In Vivo
}

\author{
Guangchang Pang ${ }^{*}$, Yufang Wang, Junbo Xie, Qingsen Chen and Zhihe Hu \\ Tianjin Key Laboratory of Food Biotechnology; People's Republic of China; Department of Bioengineering; Tianjin \\ University of Commerce; Tianjin - People's Republic of China
}

\begin{abstract}
FcRn (neonatal Fc receptor) plays an important role in IgG transportation, antigen presentation and signal transmission. In this study, the complement fixation test and flow cytometry test were performed to verify whether the heterologous antibody could be transmitted to the serum or leukocyte with $F c \gamma R$ ( $\mathrm{Fc}$ gamma receptor) across the intestinal mucosa. The results showed that rabbit anti-bovine IgG could be detected in both the serum and the leukocytes, which indicated that the heterologous antibody could transport across the intestinal mucosa to enter the blood and be effectively delivered to the leukocytes with $F c \gamma R$. In addition, the results also showed that the rabbit anti-bovine IgG still could be detected in the leukocyte group $(P=0.044<0.05)$ after 21 days. It indicated that the rabbit IgG could exist in the body for a long term (up to 21 days) after being transported to the cells containing $F c \gamma R$.
\end{abstract}

Key words: FcRn; Heterogeneous IgG transport; Complement fixation test; Fc $\gamma R$; Gastrointestinal barrier

\section{INTRODUCTION}

The neonatal $\mathrm{Fc}$ receptor $(\mathrm{FcRn})$ is an $\mathrm{MHC}$ (major histocompatibility complex) Class I-like molecule that can protect $\operatorname{IgG}$ and albumin from catabolism and mediate the transportation of $\mathrm{IgG}$ across epithelial cells (Kuo et al. 2010). FcRn transfers the acquired immunity by the mother during her early years to the fetus via the placenta, and the main mediator for the delivery to infants is breast feeding. In addition to its crucial roles in exerting IgG transportation, FcRn has other various functions. Professional APCs (monocytes, macrophages and some dendritic cell (DCs) subsets) express FcRn (Zhu et al. 2001) and are in charge of carrying the antigen across the gastrointestinal barrier (Yoshida et al. 2004), controlling and prolonging the life of IgG (Ward et al. 2003) and combining with albumin, controlling the transportation, circulation and life of albumin (Chaudhury et al. 2003; Kim 2005; Andersen et al. 2006).

The process of FcRn combining with IgG requires strict $\mathrm{pH}$ dependency, i.e., when in $\mathrm{pH}$ 5.0-6.0, $\mathrm{FcRn}$ and $\mathrm{IgG}$ combine via nanomolar appetency. Once the environment changes to be $\mathrm{pH} 7.0$, the combination will reduce by over 2 levels (Popov and Hubbard 1996). In general, the $\mathrm{pH}$ near the intestinal epithelium is lower (6.0 6.5); thus, the IgG that reaches the surface of the intestinal epithelial cells can combine well with the FcRn that expresses on top of the epithelial cells, then enter into the cells via the endocytosis of FcRn mediation after the FcRn-IgG compound goes through the epithelial cell and gets to the base surface ( $\mathrm{pH}$ over 7.0). Therefore, the IgG here will

\footnotetext{
*Author for correspondence: pgc@tjcu.edu.cn
} 
be released again and combine with multiple cells' Fc $\gamma R$ or enter into the blood for circulation. Experiments also proved that the FcRn existing on the surface of epithelium mucosal cells has the role of transporting $\mathrm{IgG}$ bi-directionally (Claypool et al. 2004); consequently, FcRn exerts a pivotal role during the process of immunological recognition and response mediated by antibody.

FcRn plays an important role in $\mathrm{IgG}$ transportation, life control, intestinal tract antigen presentation and signal transmission (Roopenian and Akilesh 2007). Therefore, it has extensive development and application prospects in the fields of prolonging the engineering of monoclonal antibody life (Gurbaxani et al. 2013), conducting therapy for all kinds of disease, including cancer (Chee et al. 2014), synergism of oral vaccines (Devriendt et al. 2012) and autoimmune disease (López-Expósito et al. 2011; Rothe and Rubbert 2011), etc. According to the binding site of $\mathrm{FcRn}$ and $\mathrm{IgG}$, taking the $\mathrm{Fc}$ fusion protein of $\operatorname{IgG}$ as the medicine (or vaccine) and FcRn as the carrier, the oral medication of biological products (Bitonti and Dumont 2006; Datta-Mannan et al. 2007) can be carried out across the epithelial cells via transcytosis. Some studies have been reported to fuse the Fc segment of IgG1 with auxin. Such a recombination of Fcauxin fusion proteins' transport efficiency is far higher than the individual auxin (Jones and Waldman 1972), and some people prove that the Fc fusion protein taken orally may transport via FcRn, thereby promoting cross mucosa (Walsh and Jefferis 2006). It is believed that this will provide a new approach for the therapy of disease and cancer.

In recent years, the monoclonal antibody has been applied to cure multiple diseases (especially cancer) in clinic, and great progress has been made in preparing and adapting the balb/c mouse monoclonal antibody. However, there are several puzzles that need to be overcome (Shuptrine et al. 2012): 1. It costs too much and is applied mainly in cancer therapy, which is hard to promote the application for general treatment of diseases; 2 . The monoclonal antibodies are needed to reach the target site effectively. As the transportation system, FcRn in particular is needed to help to transport the antibodies cross the blood brain barrier and multiple barrier systems. To a great extent, all of the antibody's life and concentration depend on its affinity with FcRn (Buss et al. 2012; Cooper et al. 2013). To conquer the life and transportation issues of monoclonal antibodies, extensive research shall be done for FcRs, especially for FcRn (Albanesia and Daëron 2012; $\mathrm{Ng}$ et al. 2014). Up to now, few investigations has been done to indicate whether or not the heterologous antibody can be absorbed via $\mathrm{hFcRn}$ (human neonatal Fc receptor).

Pang et al. (Pang et al. 2014) proved that the heterogeneous antibody can indeed transport across the gastrointestinal mucosa barrier through FcFn. Moreover, it can directly transport the heterogeneous antibody to other leukocytes with $\mathrm{Fc}$ receptors $(\mathrm{FcR})$ from the intestinal epithelium, which may not only protect the heterogeneous antibody from degradation or exclusion, thus prolonging its half-life, but also may exert the protective role of antibody-dependent cellmediated cytotoxicity (ADCC). Interestingly, the results indicated that the affinity between $\mathrm{hFcRn}$ and rabbit $\mathrm{IgG}$ is not only greater than other animals' (sheep, horse, cattle) antibodies, but also even greater than that of humans. Obviously, if the heterogeneous antibody can enter into body via oral intake, it will combine with leukocytes with multiple FcyRs under the epithelium, which can protect it for exerting specific immunity functions and prolong its half-life. If this condition generally exists in mammals, especially human, it will develop a new path to cure many diseases through oral intake of heterogeneous antibodies, including cancers. In this study, in order to evaluate whether the rabbit antibody can transport to the human body via $\mathrm{hFcRn}$, the rabbit anti-bovine polyclonal antibody was administered by the young healthy volunteers. Then the complement fixation test was used to detect the rabbit anti-bovine antibody in the subjects' peripheral blood leucocyte and plasma.

\section{MATERIAL AND METHODS}

\section{Material and reagents}

The freeze-dried complement (C3), hemolysin, sheep red blood cells and FITC-labeled bovine IgG were provided by Shijiazhuang Huarui Innovation Biotechnology Co., Ltd. The white blood cell separating medium was provided by Beijing Mr. Lai Treasure Technology Co. Ltd. Freund's complete and incomplete adjuvant was provided by Tianjin HaoSi Biological Technology Co., LTD. The Red Blood Cell Lysis Buffer, whole blood and organization diluent and the 
HANKS scrubbing solution were purchased from Tianjin Hao Ocean Biological Technology Co., Ltd. The standard rabbit serum was provided by Tianjin Kori Biological Technology Development Co., LTD. The New Zealand White Male Rabbits, body weight: $2.5-3.0 \mathrm{~kg}$, were purchased from Tianjin President Francois Experiment Supplies Co., Ltd.

\section{Apparatus}

Thermo Labsystem MK3 Microplate Reader was made by Thermo Electron Corporation; highspeed refrigerated centrifuge (3K15) was provided by Sigma-Aldrich Co. LLC; Flow FC500 flow cytometer (FCM) was made by Beckman Coulter, Inc.TE2000 Fluorescence microscope was made by NIKON Instruments CO. Ltd; 96-pore plate (655209) was provided by CKRG Biological Engineering Technology \& Services Co. Ltd.

\section{Preparation of rabbit anti-bovine IgG}

Separate the serum after the fresh bovine blood was coagulated, precipitate with different saturated ammonium sulfates, then fractionate and separate with desalting. The purity of the obtained IgG was higher than $95 \%$. Twelve healthy male white rabbits from New Zealand were fed for 1 week to adapt to the environment. $5 \mathrm{~mL}$ of rabbit blood was gathered via the vein before the date of the primary immunization, and the serum was separated and saved under cold condition. The separated bovine $\operatorname{IgG}$ (antigen) was mixed with Freud's complete adjuvant with balanced amounts, sufficiently emulsified to be emulsion for the primary immunization. Use the multipoint injection on the back's subcutaneous tissue, inject $1 \mathrm{~mL}$ emulsion for each rabbit; the second immunization is conducted in the next two weeks. Mix the bovine IgG with an equal amount of Freund's incomplete adjuvant to prepare as emulsion. The immunization method and dosage were the same as in the first one. Conduct the third and fourth booster immunization in the $3^{\text {rd }}$ and $4^{\text {th }}$ weeks. Take the venous blood in the edge of the ear 5 days after the $4^{\text {th }}$ immunization, measure the antiserum's titer with the double immunodiffusion method. If the titer hasn't reached the required amount, continue the intravenous injection to conduct the booster immunization. When the antiserum titer reached or exceeded 1:32, whole blood could be used, and then the antiserum could be separated. By means of the different saturability of ammonium sulfate precipitation, separate the rabbit anti-bovine IgG. After dialyzing and desalting, then the purified rabbit anti-bovine $\operatorname{IgG}$ was obtained. After low temperature freezing and drying, the purity was over $95 \%$.

\section{Separation of leukocyte from the blood}

Take the fresh anti-coagulant blood $4 \mathrm{~mL}(\mathrm{~V})$ to add into the isometric tissue diluent $(\mathrm{V})$. Mix sufficiently and carefully add the leukocyteseparating medium (2V) slowly on the liquid level, centrifuge for $25 \mathrm{~min}$ at $500 \mathrm{~g}$. At this time, the centrifuge tube is separated into 4 layers from top to bottom. The first layer is plasma; the second layer is cyclic annular milky leukocyte; the third layer is the separating medium with slightly turbidity, and certain leukocytes are gathered in this layer; and the fourth layer is made of erythrocytes. Carefully suck up the first layer and discard, collect the second, third and fourth layers, put them into the test tube, and wash them with a certain volume of Hanks solution. Even after mixing, centrifuge for $30 \mathrm{~min}$ continually with $500 \mathrm{~g}$ centrifugal force, take the sediment after the first wash, add erythrocyte lysate (generally add 3 times of the original blood volume) to split the erythrocytes. After being washed again, the white sediment (leukocytes) was obtained.

\section{Intestinal mucosa transportation of IgG}

10 healthy, young university student volunteers were recruited from Tianjin University of Commerce. Before the experiment, all of them signed the consent, safety and responsibility agreements. The testers may conduct the experiment through a one-week diet adjustment. Each tester abstains from food before the official experiment. On the day of the experiment, the venous blood was gathered at 9:00 AM as control. The volunteers took rabbit anti-bovine $\operatorname{IgG} 150$ $\mathrm{mg} / \mathrm{kg}$ immediately after lunch (12:00 noon) (drink via a normal, disinfected saline solution), and the venous blood was collect in $4 \mathrm{~h}$. Separate the serum with the centrifugation $(1000 \mathrm{~g}, 10 \mathrm{~min})$ at $4^{\circ} \mathrm{C}$.

This experiment used the anti-bovine $\mathrm{IgG}$ antigen to test the specific rabbit anti-bovine $\mathrm{IgG}$ antibody. Primarily, after taking the rabbit antibovine $\operatorname{IgG}$ orally $(4 \mathrm{~h})$, using the bovine IgG as the antigen, detect whether the rabbit anti-bovine IgG exists in the blood and leukocytes, thus judging whether this heterologous antibody $\operatorname{IgG}$ can transport across the intestinal mucosa barrier. 
In the indicating system, one pair of the antigenantibody compound formed from sheep erythrocyte and hemolysin is called a sensitized erythrocyte. Bovine $\operatorname{IgG}$ and rabbit anti-bovine $\mathrm{IgG}$ used for the pending test also consisted of one pair of the antigen-antibody compound. While conducting the CRT experiment, in the indicating system, the sensitized erythrocyte and rabbit antibovine $\mathrm{IgG}$ used for the pending test can combine with the complement. Thus, the limited complement existed in the competitive complement system (C3). Eventually, according to the condition of hemolysis, we determine whether or not the rabbit anti-bovine $\operatorname{IgG}$ exists in the blood (or leukocytes). If there is no hemolysis, it expresses as CFT positive, which means that the heterologous antibody $\operatorname{IgG}$ may transport across the gastrointestinal mucosa. Conversely, if there is hemolysis, it expresses as CFT negative, which means that the per-oral heterologous antibody IgG cannot transport to the blood across the gastrointestinal mucosa. Because the hemoglobin will release after the breakdown of the erythrocytes in the hemolysis, after the normal test, put it into a refrigerator at $4{ }^{\circ} \mathrm{C}$ for $12 \mathrm{~h}$; the erythrocyte that has not broken down will precipitate as sediment. The hemachrome in supernate of the sample was detected with ELISA at $384 \mathrm{~nm}$. Thus we may further measure the hemolysis condition for sheep red blood cells via quantification.

While conducting the experiment, we respectively set the tested serum control (before rabbit antibovine $\operatorname{IgG}$ taken orally), complement control, antigen control, negative serum control and positive serum control. The tested serum was taken as the sample testing object. The criteria of the experimental result are: the tested serum control, complement control, antigen control, negative serum control all show complete hemolysis, while the positive serum control and erythrocyte control do not show complete hemolysis.

\section{Flow cytometry tests}

Take two flow tubes (1 and 2), mix the fresh anticoagulant blood around 8 to 10 times, put 100 $\mu \mathrm{L}$ of anticoagulant blood into both flow tubes, and then add $20 \mu \mathrm{L}$ of bovine IgG marked with FITC into Tube No. 2, leaving Tube No. 1 to be the control tube. After adding the antigen, rotate it and blend it together, let it sit for $20 \mathrm{~min}$ at room temperature in the dark. After the antigen and the blood react sufficiently, add $2 \mathrm{~mL}$ of $10 \times$ hemolysin into each tube, mix evenly and leave them for 8 to $10 \mathrm{~min}$ under room temperature without sunlight. Pay attention; the hemolysis time should not be too long in order to prevent damaging the leukocyte. Take out the tube. The solution will be clarified at this time. Centrifuge for $5 \mathrm{~min}$ at $300 \mathrm{~g}$, take out the tube and vertically pour in $2 \mathrm{ml}$ of phosphate buffer solution (PBS). Rotate to mix evenly, centrifuge for $5 \mathrm{~min}$ at $300 \mathrm{~g}$ under room temperature, take out the tube, discard the clear liquid, mix evenly, then add $0.5 \mathrm{~mL}$ PBS and rotate evenly. Place it in a $4^{\circ} \mathrm{C}$ refrigerator and store in the dark. Conduct the flow cytometry test within $4 \mathrm{~h}$. While testing, use the Acquisition Template Files software to obtain the pattern file, use the Cell Quest Pro software to set and adjust the instrument and obtain the data via the preset pattern files.

\section{Fluorescence microscopy detection}

The blood pretreatment method was the same as with the flow cytometry test: Take one drop of the sample to drip to the glass slide (the thickness of about $0.17 \mathrm{~mm}$ ), add the cover glass, let this sample distribute evenly, then observe under the fluorescence microscope and take pictures.

\section{Data analysis}

All of the data were analyzed using the statistical software package Statistical Product and Service Solutions (Version 16). Independent-sample ttests were used for the analysis.

\section{RESULTS AND DISCUSSION}

After the volunteers take the rabbit anti-bovine $\mathrm{IgG}$, the rabbit anti-bovine $\operatorname{IgG}$ in the serum sample was processed via the complement fixation test (CFT). The hemolysin generated in the hemolysis was detected at $384 \mathrm{~nm}$. The results are shown in Table 1. Take the serum collected before the testers take the rabbit anti-bovine IgG as the control group, and the serum collected after $4 \mathrm{~h}$ of the administration as the experimental group. The pairing $\mathrm{T}$ testing results showed that the control group and experimental group had obvious differences $(\mathrm{P}=0.015<0.05)$, which meant that rabbit anti-bovine $\operatorname{IgG}$ can be transported to the blood across the intestinal mucosa per os. After 21 days, the content of rabbit anti-bovine IgG in the serum has no obvious differences compared with 
the control $(\mathrm{P}=0.073>0.05)$. That is to say, there is no rabbit anti-bovine $\mathrm{IgG}$ in the serum after 21 days. Four hours after the volunteers take the rabbit anti-bovine $\operatorname{IgG}$, the heterologous antibody actually can enter the blood across the $\mathrm{hFcRn}$ intestinal mucosa barrier via the epithelial cells, but the rabbit anti-bovine $\operatorname{IgG}$ will metabolize or be eliminated after a period of time due to the free state.

Table 1 - Rabbit anti-bovine IgG in the serum (O.D 384 value).

\begin{tabular}{ccc}
\hline $\begin{array}{c}\text { Control Group } \\
\text { (before eating) }\end{array}$ & $\begin{array}{c}\text { Experimental } \\
\text { Group } \\
\text { (4h after eating) }\end{array}$ & $\begin{array}{c}\text { Experimental } \\
\text { Group } \\
\text { (21d after eating) }\end{array}$ \\
\hline 1.161 & 1.002 & 1.159 \\
1.153 & 0.924 & 1.147 \\
1.252 & 1.033 & 1.247 \\
1.372 & 0.997 & 1.365 \\
1.031 & 0.986 & 1.033 \\
1.245 & 1.085 & 1.241 \\
0.972 & 0.959 & 1.247 \\
1.616 & 0.921 & 1.558 \\
1.762 & 1.109 & 1.689 \\
1.158 & 1.064 & 1.145 \\
\hline
\end{tabular}

Table 2 - Rabbit anti-bovine $\operatorname{IgG}$ of leukocyte combination (OD384 value).

\begin{tabular}{ccc}
\hline $\begin{array}{c}\text { Control } \\
\text { Group }\end{array}$ & $\begin{array}{c}\text { Experimental } \\
\text { Group (4h) }\end{array}$ & $\begin{array}{c}\text { Experimental } \\
\text { Group (21d) }\end{array}$ \\
\hline 0.890 & 0.667 & 0.882 \\
0.845 & 0.701 & 0.827 \\
0.879 & 0.689 & 0.868 \\
1.000 & 0.828 & 1.002 \\
0.854 & 0.692 & 0.846 \\
0.872 & 0.676 & 0.863 \\
0.889 & 0.871 & 0.869 \\
0.952 & 0.845 & 0.925 \\
0.946 & 0.696 & 0.934 \\
0.813 & 0.787 & 0.808 \\
\hline
\end{tabular}

Many leukocytes can express FcR, including myeloid cells of all types and some lymphoid cells such as B cells, NK cells and NKT cells (Albanesia and Daëron 2012). Therefore, we investigate whether or not the rabbit anti-bovine IgG is exiting in the leukocyte. The results are shown in Table 2 . The pairing $\mathrm{T}$ testing results indicated that experimental group and the control group showed obvious differences $(\mathrm{P}=0.027<0.05)$. The $\mathrm{F} c \gamma \mathrm{R}$ of the leukocyte in the blood does indeed combine the heterogeneous rabbit anti-bovine $\mathrm{IgG}$, and the heterogeneous antibody can enter into the intestinal epithelium across the intestinal mucosa barrier after being taken orally and absorbed through the hFcRn cells of the intestinal mucosa system. The rabbit antibovine IgG was delivered to the cells with $\mathrm{Fc} \gamma \mathrm{R}$, and then enters into the blood for circulation (Pang et al. 2014). After 21 days, the content of rabbit anti-bovine $\operatorname{IgG}$ in the leukocyte had obvious difference compared with the control $(\mathrm{P}=0.044<0.05)$, which meant that the rabbit antibovine IgG still existed in the leukocyte.

In this study, it was indicated that the epithelial cells, microfold cells, dendritic cells and several kinds of APC cells (antigen resenting cells) with FcRn expressed in the intestinal mucosa system actually may transport rabbit anti-bovine IgG to the lamina propria of the intestinal epithelium, gut-associated lymphoid tissue (GALT) or Peyer's patches (PP), while at $\mathrm{pH} 7.0$, the heterogeneous rabbit anti-bovine $\mathrm{IgG}$ will be transported to multiple immune cells with $\mathrm{Fc} \gamma \mathrm{R}$ and exert the role of ADCC. To trace the persistence time of rabbit anti-bovine $\operatorname{IgG}$ in the body, we detected it in the serum and leukocytes after 21 days. The results showed that the leukocytes still contained a certain amount of rabbit anti-bovine IgG. The reasons for this may be: after the $\mathrm{Fc}$ end of the heterologous antibody and the $\mathrm{Fc}$ on the leukocyte combine, the species variation of the antibody Fc segment is "buried." However, the part to identify the foreign heterologous antibody is just the $\mathrm{Fc}$ segment, thus the rabbit anti-bovine $\operatorname{IgG}$ that combined with $\mathrm{Fc}$ may avoid the identification of the engine body and the role of degradation and elimination, so the life can be prolonged effectively. We can see that the rabbit anti-bovine IgG taken orally can be absorbed by the cells of FcRn. Herein at least some parts are transported directly to other cells that express Fc $\gamma \mathrm{R}$, which then exert the specific immunity response and the protection for rabbit anti-bovine IgG and the role of life extension.

To further confirm whether or not the rabbit antibovine $\operatorname{IgG}$ taken orally really is combined with the Fc $\gamma \mathrm{R}$ positive cytomembrane, and whether or not it effectively prolongs the life, we may mark the bovine IgG (FITC labeled bovine IgG) with fluorescein isothiocyanate and test the leukocyte after 21 days via Flow Cytometer (FCM). The results are shown in Figure 1 A-G.

The data of both the scatter diagram and the histogram meant that there is a fluorescence signal in the blood pending testing, that is, the bovine IgG marked with FITC is identified via rabbit anti-bovine $\mathrm{IgG}$, then absorbed and transported to the leukocyte with Fc $\gamma$ R. 


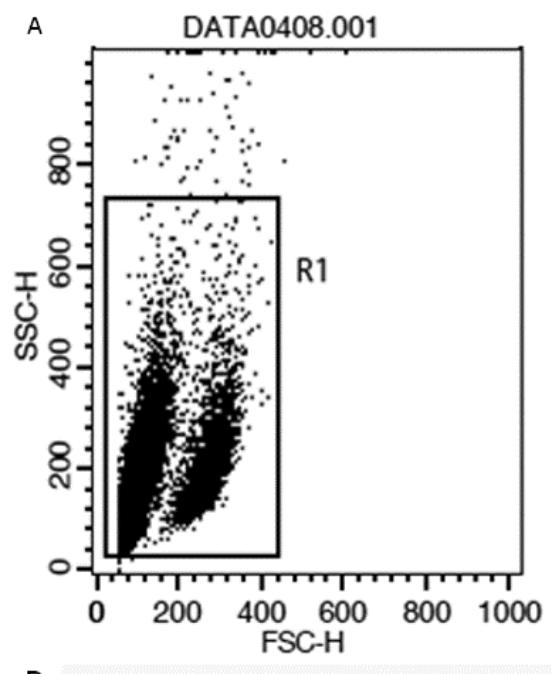

D

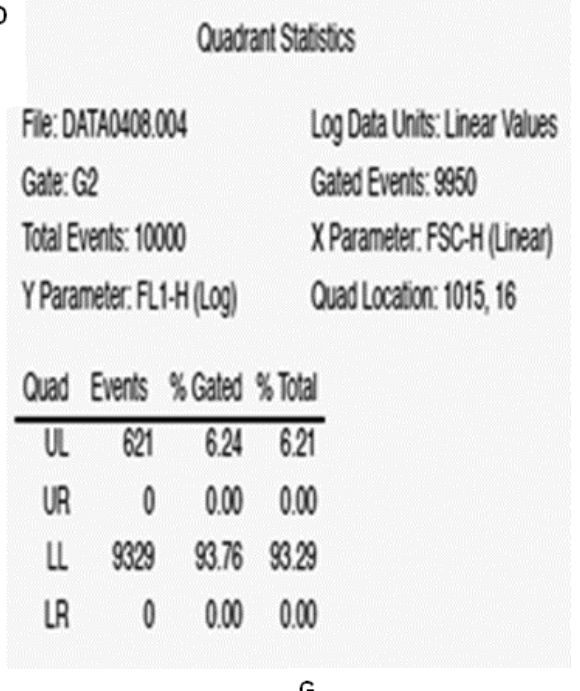

G
B
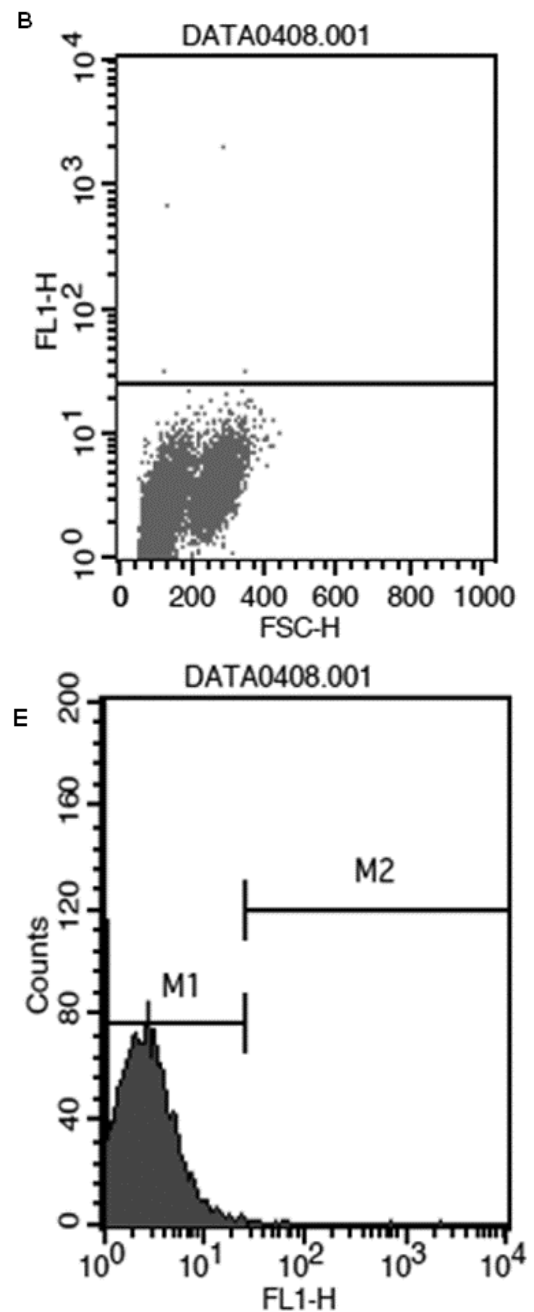

Histogram Statistics
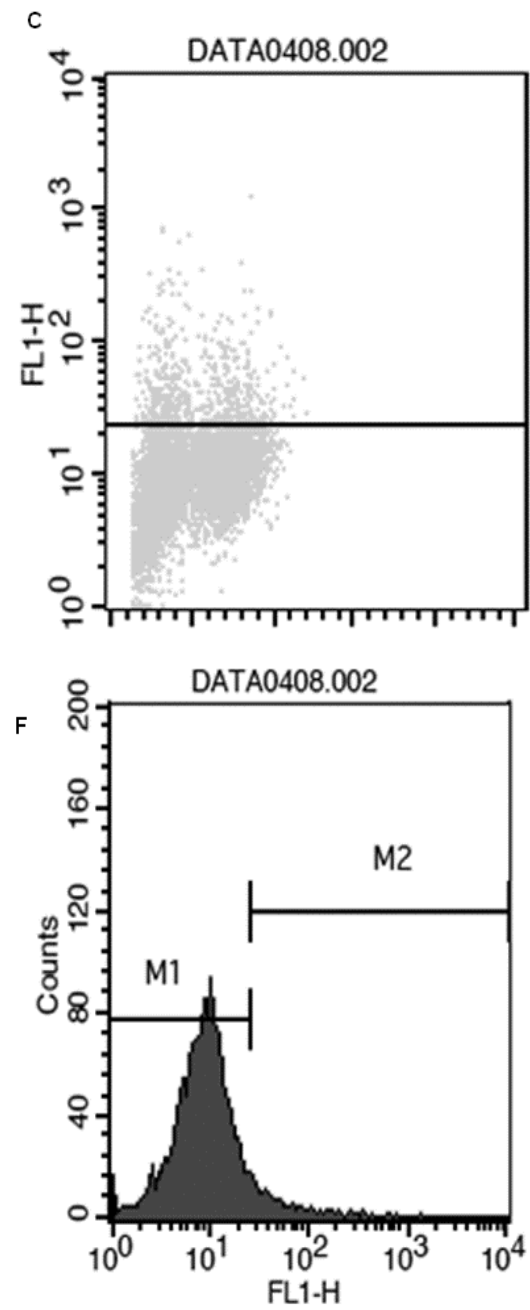

Log Data Units: Linear Values

Gated Events: 10000

$\times$ Parameter: FL1-H (Log)

Total Events: 10000

\begin{tabular}{rrrrr} 
Marker & Left, Right & Events & $\%$ Gated & $\%$ Total \\
\hline All & 1,9910 & 10000 & 100.00 & 100.00 \\
M1 & 1,25 & 9377 & 93.77 & 93.77
\end{tabular}

Figure 1 - The detection maps of FCM (c) and (f) are FSC-SSC two-dimensional scatter diagrams and FLI histograms, respectively, after the leukocyte in the fresh blood combines the bovine IgG marked with FITC. In Fig (a), the region R1 means the leukocyte, (b) and (e) represent region R1 cells' fluorescence signal in channel FL1, (b) is the scatter diagram, and (e) is the histogram. Analyzed via Cellquest software, the scatter diagram shown in (d) means, in the cells in region R1, $6.24 \%$ is detected with remarkable reinforced fluorescence signal; the analysis result of histogram (g) indicates that the cells with remarkable reinforced fluorescence signal cover $6.29 \%$ of cells in region $\mathrm{R} 1$.

We incubated the processed fresh anticoagulant blood with bovine IgG marked with FITC, and observed the cells marked with fluorescence by fluorescence microscopy (Fig. 2). After incubating the reaction between the antigen marked with
FITC and the fresh blood that was collected and processed via rabbit anti-bovine $\operatorname{IgG}$ in 21 days, the cells with fluorescence signal were detected, which indicated that the heterologous antibody - 
rabbit anti-bovine IgG actually existed in the tested blood.

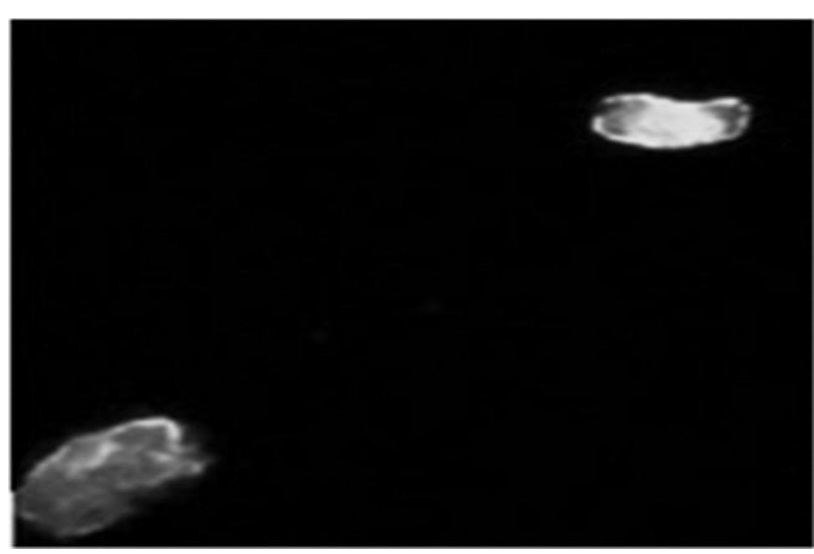

Figure 2 - The antigen labeled with FITC under the fluorescent microscope.

\section{CONCLUSIONS}

In this study, it was indicated that the heterologous antibody - rabbit anti-bovine IgG actually may be transported into the blood across the intestinal tract $\mathrm{hFcRn}$ and the intestinal mucosa barrier. After 21 days, the rabbit anti-bovine IgG didn't exist in the serum, which meant that the free-state antibody that enters into the blood was quickly metabolized and eliminated. However, the rabbit anti-bovine IgG that combined in the leukocyte still existed. It indicated that, after transporting the rabbit antibovine $\mathrm{IgG}$ to the lamina propria of the intestinal epithelium, gut-associated lymphoid tissue or Peyer's patches, hFcRn could transfer it to the near various leukocytes with $\mathrm{Fc} \gamma \mathrm{R}$. Because the Fc end and the receptor combined, the heterogeneous rabbit anti-bovine IgG's Fe structural domain was sheltered. The IgG's Fc structural domain was the key position through which the body identify its own and the foreign IgG. The engine body cannot identify and eliminate the combined rabbit antibovine IgG as "foreign matter", thus effectively prolonged its life. Consequently, it can exert ADCC and a series of immune responses and protective effects while the specific antigen enters (or invades).

\section{ACKNOWLEDGEMENTS}

This research was supported by the National Natural Science Foundation of China (No. 31371773).

\section{REFERENCES}

Albanesia M, Daëron M. The interactions of therapeutic antibodies with $\mathrm{Fc}$ receptors. Immunol Let. 2012; 143(1): 20-27.

Andersen JT, Dee QJ, Sandlie I. The conserved histidine 166 residue of the human neonatal Fc receptor heavy chain is critical for the $\mathrm{pH}$-dependent binding to albumin. Eur J Immunol. 2006; 36(11): 3044-3051.

Bitonti AJ, Dumont JA. Pulmonary administration of therapeutic proteins using an immunoglobulin transport pathway. Adv Drug Deliv Rev. 2006; 58(10): 1106-1118.

Buss NA, Henderson SJ, McFarlane M, Shenton JM, de Haan L. Monoclonal antibody therapeutics: history and future. Curr Opin Pharmacol. 2012; 12(5): 615622.

Chaudhury C, Mehnaz S, Robinson JM, Hayton WL, Pearl DK, Roopenian DC, et al. The major histocompatibility complex related $\mathrm{Fc}$ receptor for IgG (FcRn) binds albumin and prolongs its lifespan. $J$ Exp Med. 2003; 197(3): 315-322.

Claypool SM, Dickinson BL, Wagner JS, Johansen F, Venu N, Borawski JA, et al. Bidirectional Transepithelial IgG Transport by a Strongly Polarized Baso-lateral Membrane Fc $\gamma$-Receptor. Mol Bio Cell, 2004;15(4):1746-1759.

Cooper PR, Ciambrone GJ, Kliwinski CM, Maze E, Johnson L, Li Q, et al. Efflux of monoclonal antibodies from rat brain by neonatal Fc receptor, FcRn. Brain Res. 2013; 1534: 13-21.

Gurbaxani B, Dostalek M, Gardner I. Are endosomal trafficking parameters better targets for improving $\mathrm{mAb}$ pharmacokinetics than FcRn binding affinity? Mol Immunol.2013; 56(4): 660-674.

Datta-Mannan A, Witcher D, Tang R Y, Watkins J, Jiang W, Wroblewski VJ. Humanized IgG1 variants with differential binding properties to the neonatal Fc receptor: relationship to pharmacokinetics in mice and primates. Drug metabolism and disposition: the biological fate of chemicals 2007; 35(1): 86-94.

Devriendt B, De Geest BG, Goddeeris BM, Cox E. Crossing the barrier: Targeting epithelial receptors for enhanced oral vaccine delivery. J Control Release, 2012;160(3), 431-439.

Jones E, Waldman T. The mechanism of intestinal uptake and transcellular transport of $\mathrm{IgG}$ in the neonatal rat. J Clin Invest.1972; 51:2916-2927.

Kim J, Bronson CL, Hayton WL, Radmacher MD, Roopenian DC, Robinson JM, et al. Albumin turnover: FcRn-mediated recycling saves as much albumin from degradation as the liver produces. Am J Physiol Gastrointest Liver Physiol. 2005; 290(2): $352-360$. 
Kuo TT, Baker K, Yoshida M, Qiao S, Aveson VG, Lencer WI, et al. Neonatal Fc receptor: from immunity to therapeutics. J Clin Immunol. 2010; 30(6), 777-789.

López-Expósito I, Järvinen KM, Castillo A, Seppo AE, Song Y, Li XM. Maternal peanut consumption provides protection in offspring against peanut sensitization that is further enhanced when coadministered with bacterial mucosal adjuvant. Food Res Int.2011; 44(6): 1649-1656.

$\mathrm{Ng}$ CM, Loyet KM, Iyer S, Fielder PJ, Deng R. Modeling approach to investigate the effect of neonatal Fc receptor binding affinity and antitherapeutic antibody on the pharmacokinetic of humanized monoclonal anti-tumor necrosis factor-a IgG antibody in Cynomolgus monkey. EurJ Pharm Sci. 2014; 51(1):51-58.

Pang G, Qiao D, Chen Q, Hu Z, Xie, J. Heterogeneous IgG interacts with FcRn and its transport across gastrointestinal barrier. Food Agricult Immunol. 2014; DOI: 10.1080/09540105.2014.918588

Popov S, Hubbard JG. The stoichiometry and affinity of murine Fc fragments with the MHC class-I related receptor, FcRn. Mol Immunol. 1996; 33(6):521-530.

Roopenian DC, Akilesh S. (2007). Modeling approach to investigate the effect of neonatal $\mathrm{Fc}$ receptor binding affinity and anti-therapeutic antibody on the pharmacokinetic of humanized monoclonal antitumor necrosis factor- $\alpha \operatorname{IgG}$ antibody in cynomolgus monkey. Nat Rev Immunol. 2007; 7: 715-725.
Rothe A, Rubbert A. Recombinant proteins in rheumatology-recent advances. New Biotechnol. 2011; 28: 502-510.

Shuptrine CW, Surana R, Weiner LM. Monoclonal antibodies for the treatment of cancer. Semin Cancer Biol. 2012;22(1): 3-13.

Walsh G, Jefferis R. Post-translational modifications in the context of therapeutic proteins. Nat Biotechnol. 2006; 24(10): 1241-1252.

Ward ES, Zhou J, Ghetie V, Ober RJ. Evidence to support the cellular mechanism involved in serum IgG homeostasis in humans. Int Immunol. 2003; 15(2): 187-195.

Yoshida M, Claypool SM, Wagner JS, Mizoguchi E, Mizoguchi A, Roopenian DC, et al. Human neonatal Fc receptor mediates transport of $\mathrm{IgG}$ into luminal secretions for delivery of antigens to mucosal dendritic cells. Immunity 2004; 20(6):769-783.

Zhu X, Meng G, Dickinson BL, Li X, Mizoguchi E, Miao L, et al. MHC class I related neonatal Fc receptor for $\operatorname{IgG}$ is functionally expressed in monocytes, intestinal macrophages, and dendritic cells. J Immunol. 2001;166(5): 3266-3276.

Received: October 09, 2014; Accepted: February 24, 2015. 